\title{
Deteksi Logam Berat di Kawasan Wilayah Pesisir Semarang
}

\author{
Chrisna Adhi Suryono ${ }^{1 *}$, Baskoro Rochaddi ${ }^{2}$ \\ ${ }^{1}$ Departemen Ilmu Kelautan, ${ }^{2}$ Departemen Oseanografi \\ Fakultas Perikanan dan Ilmu Kelautan Universitas Diponegoro, Semarang \\ Kampus Tembalang, Semarang 50275 Telp/Fax. 024-7474698 \\ Email : chrisna_as@yahoo.com
}

\begin{abstract}
Abstrak
Logam berat telah ditemukan di wilayah pesisir Tugu baik dalam sedimen laut, airtanah dan air laut di daerah pesisir Tugu Semarang. Enam logam berat seperti ( $\mathrm{As}, \mathrm{Hg}, \mathrm{Cr}, \mathrm{Pb}, \mathrm{Cu}$ and $\mathrm{Fe}$ ) telah di teliti. Secara nyata terlihat bahwa logam ( $\mathrm{As}, \mathrm{Hg}, \mathrm{Cr}, \mathrm{Pb}, \mathrm{Cu}$ and $\mathrm{Fe}$ ) menurun konsentrasinya dari sedimen, air laut dan airtanah, dan konsentrasi tertinggi terdapat dalam sedimen laut dan terendah terdapat pada airtanah. Peningkatan aktifitas reklamasi, buangan air limbah baik dari industri maupun pemukiman kemungkinan menyebabkan peningkatan logam berat di wilayah pesisir Tugu Semarang.
\end{abstract}

Kata Kunci : Logam berat, pesisir, sedimen, air laut, airtanah

\begin{abstract}
Abstrack
The concentrations of metals in the marine sediment, groundwater anad marine water were found in coatal areas of Tugu Semarang. Six metals ( $\mathrm{As}, \mathrm{Hg}, \mathrm{Cr}, \mathrm{Pb}, \mathrm{Cu}$ and $\mathrm{Fe}$ ) in coastal areas in Tugu Semarang were examined. Gradually decreased concentrations heavy metas ( $\mathrm{As}, \mathrm{Hg}, \mathrm{Cr}, \mathrm{Pb}, \mathrm{Cu}$ and $\mathrm{Fe}$ ) in sediment, marine water and groundwater, and the highest concentration of metals found in marine sediment and the lowest in coatal groundwater. The increasing number of reclamation, disposal water from industrial and urban areas may be to support the increasing metals on the coastal areas of Tugu Semarang.
\end{abstract}

Keywords: Heavy Metals, Coastal, sediment, marine water, goudwater

\section{PENDAHULUAN}

Semarang sekarang telah menjadi kota Industri dan jasa hal tersebut banyak terlihat dari semakin berkembangnya kawasan industri di Kota ini. Daerah yang dicanangkan sebagai kawasan indutri adalah daerah Kecamatan Tugu. Banyak lahan peranian maupun tambak yang telah diuruk untuk kepantingan industri (Suryono and Rochaddi, 2008). Konsekuensi berubahnya suatu kawasan menjadi daerah industri adalah pencemaran, baik pada udara, air maupun tanah. Pesisir merupakan bagian dari suatu sistem yang tidak dapat lepas dari polusi, karena semua polusi yang ada di bumi akan berakhir dalalam laut maupun pesisir. Banyak penelitian yang menyatakan bahwa reklamasi memberi efek buruk pada lingkungan karena terjadinya reaksi kimiawi atantara pore water dan sedimen di kawasan reklamasi tersebut yang berdampak buruk pada lingkungan pesisir (Pagliai et al., 1985; Hall, 1989; Smith et al., 1995). Banyak penelitian tentang proses kimiawi dan fisik dalam sistim air sedimen di daerah pesisir dan estuaria. Sedimen laut banyak dipercaya bertindak selaku filter bagi banyak logam yang berasal dari daratan sebelum menetap di dasar laut dan mengakumulasinya (Tam and Wong, 2000; Yu et al.,2000; Morillo et al., 2004).

Akumulasi logam berat dalam sedimen laut seharusnya menjadi perhatian karena beberapa jenis logam akan menjadi sumber kontaminan bila karakteristik kimiawi fisik lingkungan terjadi perubahan. Markiewicz-Patkowska et al. (2005) menginformasikan dalam penelitian di laboratorium menunjukan penyerapan dan pelepasan logam ke dalam materaial tanah menuju larutan. Simpson et al (2004) menginformasikan pergerakan logam di sedimen ke dalam airtanah di daerah estuarine/ pesisir sangat di pengaruhi dan dikontrol oleh $\mathrm{pH}$ dan salinitas air. Kawasan pesisir Tugu Semarang merupakan daerah yang masih tersisa lahan pasang surut yang dipergunakan untuk tambak. Perbatasan sebelah barat kawasan tersebut adalah komplek industri kayu lapis sedangkan perbatasan sebelah timur adalah daerah bandara dan reklamasi Pantai

\footnotetext{
*Corresponding author http://ejournal.undip.ac.id/index.php/buloma

Diterima/Received : 30-01-2017

buloma.undip@gmail.com

Disetujui/Accepted : 18-03-2017
} 
Marina sedangkan sebelah selatan berupa pemukiman dan daerah industri. Melihat kondisi tersebut dimana airtanah banyak digunakan untuk industri, air laut sering pasang tinggi sehingga membanjiri daerah tambak dan buangan industri maupun polutan dari tanah reklamasi, diduga daerah pesisir tersebut akan mengalami peningkatan polutan terutama logam berat baik di airtanah, sedimen laut maupun air laut itu sendiri. Penelitian ini bertujuan megetahui konsentrasi logam berat yang terdapat dalam wilayah pesisir Tugu Semarang baik yang terdapat dalam sediment, air tanah maupun air laut.

\section{MATERI DAN METODE}

Materi yang digunakan dalam penelitian ini adalah air laut, sedimen laut dan airtanah yang diambil dari darah pesisir Tugu Semarang. Sampel sedimen dan air laut diambil pada lima titik di perairan (stasiun 1, 2, 3, 4 dan 5) sedangkan sampel airtanah diambil pada tiga titik pada sumur dangkal (stasiun A, B dan C). Sampel sedimen diambil dengan mengunakan ekman grab sedangkan sampel air laut dan airtanah menggunakan water bottle sampler. Pengulangan pengambilan sample dilakukan sebanyak tiga kali. Sampel yang diambil berupa airtanah, sedimen dasar dan air laut pada kelima titik tersebut untuk diamati kandungan logam berat dari jenis Arsen (As), Mercury ( $\mathrm{Hg})$, Chromium $(\mathrm{Cr})$, Lead $(\mathrm{Pb})$, Cuprum $(\mathrm{Cu})$ dan Ferrum $(\mathrm{Fe})$. Sampel yang berupa airtanah, sedimen dan air laut yang didapat dianalisa di laboratorium untuk menentukan kandungan logam berat dengan menggunakan alat AAS (Atomic Absorption Spectophotometry). Parameter lingkungan yang diukur pada air adalah $\mathrm{pH}$ dan salinitas dilakukan secara in-situ dengan menggunakan Water Quality Ceker (Horiba). Sampel sedimen yang diambil dikeringkan pada suhu $80^{\circ} \mathrm{C}$ selama 2 hari kemudian dihancurkan dan dilarutkan dengan $\mathrm{KNaCO} 3$ dan $\mathrm{HCl}$. Prosedur analisa kandungan logam berat dalam sediment meliputi proses destruksi dan penentuan kadar logam berat didalamnya. Prosedur analisa mengacu pada Greenberg, et al. (1985) dan Galanopoulou (2005).

\section{HASIL DAN PEMBAHASAN}

Hasil pengamatan menunjukan bahwa konsentrasi logam berat yang terdapat di airtanah daerah pesisir Tugu Kota Semarang secara umum lebih rendah bila dibandingkan dengan dengan konsentrsi yang ada di sedimen laut dan air laut. Appelo \& Postma (1996) menyatakan tingginya logam berat dalam sedimen dibandingkan dengan didalam air dikarenakan penyerapan sedimen terhadap partikel partikel logam lebih dominan karena logam mempunyai kecenderungan untuk berikatan dengan hidroksida dan bahan organik dalam sedimen. Dari pendapat tersebut dapat dimengerti mengapa logam dalam sediment lebih tinggi daripada dalam air.

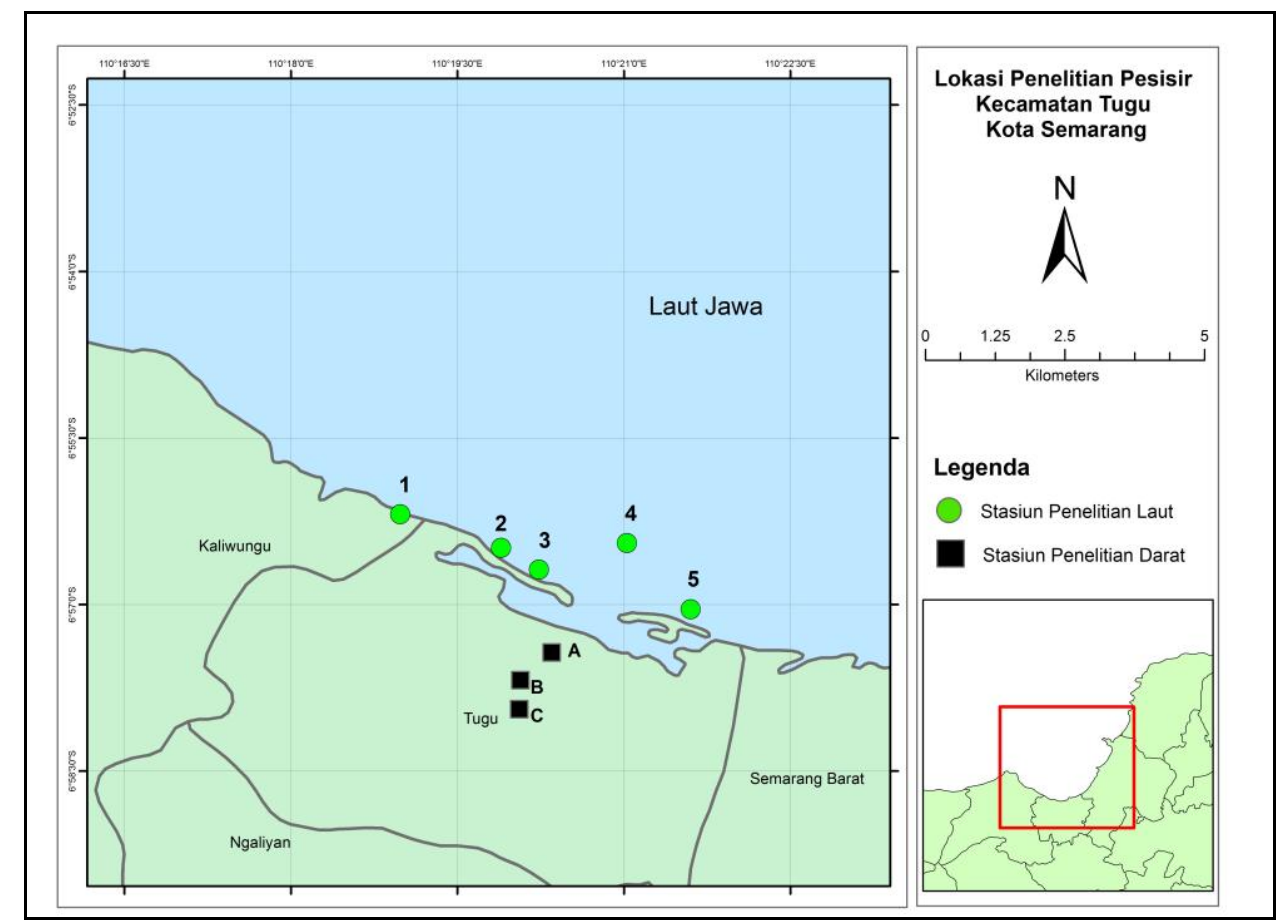

Gambar 1. Stasiun Penelitian di Pesisir Tugu Kota Semarang 
Tabel 1. Rata Rata konsentrasi logam berat dalam airtanah, air laut dan sediment laut di pesisir Tugu Semarang

\begin{tabular}{cccc}
\hline \multirow{2}{*}{ Logam Berat } & \multicolumn{3}{c}{ Airtanah } \\
\cline { 2 - 4 } & $\mathrm{A}$ & $\mathrm{B}$ & $\mathrm{C}$ \\
\hline $\mathrm{As}(\mathrm{ppb})$ & 0.54 & 0.13 & $<0.001$ \\
$\mathrm{Hg}(\mathrm{ppm})$ & $<0.005$ & $<0.005$ & $<0.005$ \\
$\mathrm{Cr}(\mathrm{ppm})$ & $<0.004$ & $<0.004$ & $<0.004$ \\
$\mathrm{~Pb}(\mathrm{ppm})$ & $<0.001$ & $<0.001$ & $<0.001$ \\
$\mathrm{Cu}(\mathrm{ppm})$ & $<0.005$ & $<0.005$ & $<0.005$ \\
$\mathrm{Fe}(\mathrm{ppm})$ & 2.81 & 2.61 & 0.2 \\
\hline
\end{tabular}

\begin{tabular}{cccccc}
\hline \multirow{2}{*}{ Air Laut } & \multicolumn{5}{c}{ Air Laut } \\
\cline { 2 - 6 } & 1 & 2 & 3 & 4 & 5 \\
\hline $\mathrm{As}(\mathrm{ppb})$ & 2.97 & 1.75 & 2.73 & 2.93 & 3.24 \\
$\mathrm{Hg}(\mathrm{ppm})$ & $<0.005$ & $<0.005$ & $<0.005$ & $<0.005$ & $<0.005$ \\
$\mathrm{Cr}(\mathrm{ppm})$ & 0.16 & 0.16 & 0.15 & 0.15 & 0.14 \\
$\mathrm{~Pb}(\mathrm{ppm})$ & 0.75 & 0.74 & 0.76 & 0.82 & 0.79 \\
$\mathrm{Cu}(\mathrm{ppm})$ & $<0.005$ & $<0.005$ & $<0.005$ & $<0.005$ & $<0.005$ \\
$\mathrm{Fe}(\mathrm{ppm})$ & 1.29 & 0.63 & 1.54 & 0.41 & 1.3 \\
\hline & & & & \\
\hline \multicolumn{2}{c}{ Logam Berat } & 1 & & Sedimen Laut & \\
& & & 3 & 4 & 5 \\
\hline $\mathrm{As}(\mathrm{ppb})$ & 285.59 & 216.3 & $<5.45$ & 307.64 & 288.74 \\
$\mathrm{Hg}(\mathrm{ppb})$ & $<0.84$ & $<0.84$ & $<0.84$ & $<0.84$ & $<0.84$ \\
$\mathrm{Cr}(\mathrm{ppm})$ & 11.44 & 11.77 & 2.01 & 7.23 & 9 \\
$\mathrm{~Pb}(\mathrm{ppm})$ & 9.86 & 10.45 & 3.94 & 7.84 & 10 \\
$\mathrm{Cu}(\mathrm{ppm})$ & 7.15 & 4.42 & 1.7 & 6.01 & 11.91 \\
$\mathrm{Fe}(\mathrm{ppm})$ & 27560 & 25910 & 1682 & 15440 & 21290 \\
\hline
\end{tabular}

Melihat data yang ada logam berat yang terdapat dalam airtanah sangat kecil dan hampir tidak terdeteksi oleh AAS hal ini tentunya masukan logam berat dari daratan dapat dikatakan sangat kecil atau tidak ada. Hal ini dapat dimengerti karena pola aliran airtanah yang ada di Semarang mengalir dari timur kearah barat mengikuti kontur topogafi Semarang (Suryono, dkk 2007). Lebih lanjut Sabdono, et al (2007) menginformasikan bahwa airtanah di pesisir Utara Pulau Jawa seperti Jakarta, Semarang dan Surabaya telah terkontaminasi oleh logam berat dan pestisida. Meskipun arah aliran tanah di Kota Semarang dari Selatan ke Utara (dari perbukitan menuju daerah pesisir). Namun di daerah pesisir Semarang kususnya daerah Tugu sebagian besar airtanah dangkalnya berupa air payau (salinitas berkisar 3-7 ppt sedangkan $\mathrm{pH} 4$ - 6). Adanya airtanah yang bersifat asam di daerah pesisir tentunya menimbulkan pertanyaan karena seharusnya airtanah tersebut bersifat basa.
Simpson et al, (2004) menyatakan bahwa pergerakan logam dari dan ke dalam sedimen dipengaruhi oleh perubahan $\mathrm{pH}$ dalam sediment. Sifat asam pada air tanah dan basa pada air laut maupun sedimen akan mengubah reaksi sehingga garam yang bersibat basa akan melepaskan logamnya menuju ke airtanah yang bersifat asam (Chen \& Jiao, 2008). Hal inilah yang diduga menyebabkan adanya logam dalam airtanah di daerah Tugu Semarang.

Secara umum keberadaan logam dalam airtanah pesisir dapat dikatakan terjadi intrusi air laut ke dalam airtanah sehingga air terasa payau. Intrusi air laut ke dalam airtanah lebih berbahaya bila logam logam yang ada di dalam garam tersebut terdapat logam berat sehinga secara kimiawi akan terlepas kearah asam (airtanah) sehingga membentuk garam dari logam berat dalam airtanah (Freeze and Cherry, 1979). Masuknya logam berat dari sedimen laut ke 
airtanah sebenarnya tidak secara kebetulan namun ada peran dari naik turunya $\mathrm{pH}$ dalam air sedimen dan salinitas (Jiao et al. 2001) and (Jiao, 2002). Kemungkinan lain yang mungkin terjadi adanya logam berat dalam air tanah dangkal di wilayah tersebut secara geologis daerah tersebut batuannya mengandung logam berat yang tinggi (Kelepertsis \& Alexakis., 2004). dan (Jiao et al. 2005). Hal tersebut juga terlihat tingginya konsentrasi logam berat di daerah penelitian yang tinggi terutama di sedimen yang diambil di perairan. Logam berat terdapat dalam sedimen laut juga mungkin dari berbagai sebab diantaranya dari daratan yang terbawa oleh air kemudian mengendap atau dari sedimen itu sendiri yang secara geologis memang tinggi logam beratnya terlebih tidak jauh dari daerah tersebut merupakan daerah reklamasi yang kemungkinan logam sudah ada pada material yang digunakan untuk reklamasi.

Chen \& Jiao (2008) menginformasikan bahwa tanah yang digunakan untuk reklamasi di teluk Shenzhen mangandung logam berat yang tinggi dengan adanya sifat asam dasar perairan maka memicu lepasnya logam dari tanah reklamasi menuju airtanah dan air laut. Selama ini di Semarang tanah yang digunakan untuk reklamasi tidak pernah dianalisa terlebih dahulu secara geokimia sehingga tidak diketahui kandungan logam berat yang ada dalam material reklamasi tersebut.

Bila dilihat kecenderungan konsentrasi logam berat dalam sedimen, air laut dan airtanah menunjukan adanya konektifitas konsentrasi logam berat antar ketiga kondisi tersebut dari yang berkonsentrasi tinggi ke konsentrasi rendah atau dari kadar garam tinggi ke rendah mengikuti hukum osmose. Bila diuji secara korelasi menunjukan bila logam berat dalam sedimen tinggi maka akan diikuti tingginya logam berat dalam air laut maupun airtanah dengan $\mathrm{r}=0,86$. Dari berbagai argumen para peneliti diatas seperti Freeze, and Cherry (1979); Jiao et al. (2005); Chen \& Jiao (2008), dapat dibahami bahwa perananan $\mathrm{pH}$ dalam sediment dasar laut sangat berberan dalam perpindahan logam antar media. Demikian juga yang terjadi di di daerah penelitian.

\section{KESIMPULAN}

Hasil penelitian dapat disimpulkan bahwa terjadi konektifitas logam berat dalam air tanah, air laut dan sedimen di wilayah pesisir Tugu Semarang.

\section{DAFTAR PUSTAKA}

Appelo, C.A.J and D. Postma 1996. Geochemistry, groundwater and pollution. A.A. Balkema. Rotterdam. 536p.

Chen, K and Jiao, J. J., 2008. Metal concentrations and mobility in marine sediment and groundwater in coastal reclamation areas: A case study in Shenzhen, China. Environ. Poll. 151:576- 584

Freeze, R.A. and J.A. Cherry.,1979. Groundwater. Prentice-Hall, Inc. New Jersey. 604p

Galanopoulou, S., 2005., Mineralogical and geochemical study of surface sediments of Keratsini harbour. Ph.D Thesis, National Technical University of Athens, Greece.

Greenberg, A.E., Trussell, R.R and. Clesseri, L.S 1985. Standard methods for the examination of water and wastewater. $16^{\text {th }}$ edition. American Public Health Association, $0515^{\text {th }}$ street NW, Washington, DC 20005.

Hall, L.A., 1989. The effects of dredging and reclamation on metal levels in water and sediments from an estuarine environment off Trinidad, West Indies. Environmental Pollution 56: 189-207.

Jiao, J.J., 2002. Preliminary conceptual study on impact of land reclamation on groundwater flow and contaminant migration in Penny's Bay. Hong Kong., Geologist (8): 14-20

Jiao, J.J., Leung, C.M., Chen, K.P., Huang, J.M., Huang, R.Q., 2005. Physical and chemical processes in the subsurface system in the land reclaimed from the sea. In: Collections of Coastal Geo-Environment and Urban Development. China Dadi Publishing House, Beijing, China, pp: 399-407

Jiao, J.J., Nandy, S., Li, H.L., 2001. Analytical studies on the impact of reclamation on groundwater flow. Ground Water. 39(6):912 $-920$

Kelepertsis, A., \& Alexakis, D. 2004. The impact of mining and metallurgical activity of the Lavrion Sulfide deposits on the geochemistry of bottom sea sediments east of the Lavreotiki Peninsula, Greece. Research $J$. Chem. Enviro. 8 (1):40-46.

Markiewicz-Patkowska, J., Hursthouse, A., Przybyla-Kij, H., 2005. The interaction of heavy metals with urban soils: sorption behaviour of $\mathrm{Cd}, \mathrm{Cu}, \mathrm{Cr}, \mathrm{Pb}$ and $\mathrm{Zn}$ with a typical mixed brownfield deposit. Environment International, 31:513-521.

Morillo, J., Usero, J., Gracia, I., 2004. Heavy metal distribution in marine sediments from 
Southwest coast of Spain. Chemosphere. 55: 431-442.

Pagliai, A., Varriale, A., Crema, R., Galletti, M., Zunarelli, R., 1985. Environmental impact of extensive dredging in a coastal marine area, Marine Pollution Bulletin 16:483-488.

Rochaddi, B dan Suryono, C.A., 2009., Pestisida organoklorin pada aqifer dangkal di wilayah pesisirkota semarang. Ilmu Kelautan, 14(3): 155-159

Sabdono, A., Suryono, C,A., Rochaddi, B and Susanti, B.T., Persistence of Organochlorine on Househole Wells of Java Urban Areas, Indonesia., Journal of Applied Sciences 8 (12): $2318-2323$

Simpson, S.L., Maher, E.J., Jolley, D.F., 2004. Processes controlling metal transport and retention as metal-contaminated groundwaters efflux through estuarine sediments. Chemosphere, 56: 821-831.

Smith, J.A., Millward, G.E., Babbedge, N.H., 1995. Monitoring and management of water and sediment quality changes caused by a harbour impoundment scheme. Environment International, 21(2):197-204.

Suryono, C.A., Rochaddi, B.. 2008., Arsenic Contamination of the Coastal Aquifer in the North Coast of Java Indonesia, Ilmu Kelautan 13 (1): 25 -30

Suryono, C.A., Sabdono, A., Rochaddi, B and Susanti, B. T., 2007., Physico-chemical Characteristic and Heavy Metal Content in Shallow Groundwater of Semarang Coastal Region., Ilmu Kelautan, 12 (4): 227 - 232

Tam, N.F.Y., Wong, Y.S., 2000. Spatial variation of metals in surface sediments of Hong Kong mangrove swamps. Environmental Pollution, 110: 195-205.

Yu, K.T., Lam, M.H.W., Yen, Y.F., Leung, A.P.K., 2000. Behavior of trace metals in the sediment pore waters of intertidal mudflats of a tropical wetlands. Environmental Toxicology and Chemistry. 19 (30) :535-542. 